\title{
Anaemia is Associated with Severe Illness in COVID-19: A Retrospective Cohort Study
}

\section{Zheying Tao}

Shanghai Jiao Tong University Medical School Affiliated Ruijin Hospital

\section{Mingyu Liu}

wuhan ninth hospital

\section{Jingyi Wu}

Shanghai Jiao Tong University Medical School Affiliated Ruijin Hospital

Jing Xu

Shanghai Jiao Tong University Medical School Affiliated Ruijin Hospital

\section{Wei Chen}

Shanghai Jiao Tong University Medical School Affiliated Ruijin Hospital

\section{Zhitao Yang}

Shanghai Jiao Tong University Medical School Affiliated Ruijin Hospital

\section{Xiaoman Xu}

wuhan ninth hospital

Ling Liu

Wuhan University Renmin Hospital

\section{Ruwu Chen}

wuhan ninth hospital

\section{Jingyuan Xie}

Shanghai Jiao Tong University Medical School Affiliated Ruijin Hospital

\section{Huiming Wang}

Wuhan University Renmin Hospital

Jialin Liu ( $\square$ ljl11243@rjh.com.cn )

Ruijin hospital, Shanghai Jiao Tong University School of Medicine https://orcid.org/0000-0001-87637351

\section{Research}

Keywords: COVID-19, anaemia, severe illness, risk factor, haemoglobin

Posted Date: July 1st, 2020

DOI: https://doi.org/10.21203/rs.3.rs-39184/v1 
License: (c) (i) This work is licensed under a Creative Commons Attribution 4.0 International License. Read Full License

Version of Record: A version of this preprint was published at Journal of Medical Virology on November 10th, 2020. See the published version at https://doi.org/10.1002/jmv.26444. 


\section{Abstract}

Background and objective:Anaemia commonly aggravates the severity of respiratory diseases, whereas thus far, no study has elucidated the impact of anaemiaonCorona Virus Disease 2019(COVID-19). The aim of this study was to evaluate the clinical characteristics of patients with anaemia, and to further explore the relationship between anaemiaand the severity of COVID-19.

METHODS:In this single-center, retrospective, observational study, a total of 222 patients were recruited, including 79 patients with anaemia and 143 patients without anaemia. Clinical characteristics, laboratory findings, disease progression and prognosis were collected and analyzed. Risk factors associated with the severe illness in COVID-19were established by univariable and multivariable logistic regression models.

Result In our cohort, compared to patients without anaemia, patients with anaemia were more likely to experience one or more comorbidities and severe COVID-19 illness, as well as higher mortality. More patients demonstrated elevated levels of C-reactive protein (CRP), procalcitonin(PCT) and creatinine in anaemia group. Levels of erythrocyte sedimentation rate(ESR), D-dimer, myoglobin, T-pro brain natriuretic peptide(T-pro-BNP) and urea nitrogen(BUN)in patients with anaemia were significantly higher than those without. In addition,the proportion of patients with dyspnoea冈elevated CRP and PCT was positively associated with the severity of anaemia. The Odd Ratio (OR) of anaemia related to the severe condition of COVID-19 was 5.07 (95\% Cl:1.82-14.18, $\mathrm{P}=0.002)$ and 3.47 (95\% Cl:1.02-11.75, $\mathrm{P}=0.046)$ after adjustment for baseline date and laboratory indices, respectively.

Conclusion:Anaemia is an independent risk factor associated with the severe illness of COVID-19, and healthcare professionals should be more sensitive to the haemoglobin levels of COVID-19 patients on admission. To avoid rapid deterioration, more intensive care should be given to patients with anaemia.

Trial registration: Ethics committee of Wuhan University People's Hospital (wdry2020-k064)

\section{Background}

Since the end of December 2019, clusters of cases of unexplained pneumonia linked to Huanan seafood market exposure have been reported in Wuhan, China. A novel member of the coronavirus family was identified in samples of bronchoalveolar lavage fluid from patients in Wuhan Jinyintan Hospital ${ }^{[1]}$, which was named severe acute respiratory syndrome coronavirus-2(SARS-CoV-2) ${ }^{[2]}$. Based on next-generation sequencing data, it has been shown that SARS-CoV-2is similar to the severe acute respiratory syndrome coronavirus (SARS-CoV)and middle east respiratory syndrome-coronavirus(MERS-CoV), with $79 \%$ and $50 \%$ sequenceidentity, respectively ${ }^{[3]}$.Moreover,laboratory findings, together with the clinical manifestation of 2019 novel coronavirus-infected pneumonia (NCIP), are analogous to what has been described in cases of SARS ${ }^{[4]}$. Notably, person-to-person transmission was confirmed among close contacts ${ }^{[5]}$. Thus far, the outbreak has rapidly spread to over the world, and the number of confirmed cases continues to grow. 
Anaemia commonly aggravates the severity of respiratory diseases,and several studies have suggested that the prevalence of anaemiawas associated with poor outcomes and increased mortality in patients

with community-acquired pneumococcal pneumonia ${ }^{[6][7]}$. In 99 COVID-19 patients transferred to Jinyintan Hospital, $51 \%$ of patients showed adecreasing tendency in haemoglobin levels ${ }^{[8]}$.Ina study on 1099 laboratory-confirmed COVID-19 cases, it was shown that severe patients had significantly lower haemoglobinlevels than those diagnosed as non-severe cases. It should be noted that, the decline inhaemoglobin was more pronounced in patients who reached to the composite endpoint incorporating admission to the intensive care units (ICUs), or mechanical ventilation, or death, thus indicating that low haemoglobinlevels might be related to poor progression and prognosis ${ }^{[9]}$. Therefore, anaemia could possibly be a risk factor for severe disease in COVID-19.

In this study, we aimed to evaluate the impact of anaemia on the clinical course of COVID-19 patients. We particularly focused on the differences between anaemicpatients and non-anaemicpatients. We sought to reveal the relationship between anaemia and the severity of COVID-19 pneumonia, with the aim of contributing to the early recognition of disease severity and to extend the understanding of anaemia in COVID-19 patients.

\section{Method}

\section{Study design and patient involvement}

This retrospective, single-centre, observational study was performed at the Wuhan Ninth Hospital. Patients diagnosed with 2019 novel coronavirus (2019-nCoV)-infected pneumonia according to World Health Organization (WHO) interim guidance were enrolled in this study. Patients were excluded if:1) they were younger than 18 years old; 2) had missing data on haemoglobin levels and outcomes. Finally, 222 patients were included. The study was approved by The Ethics Commission of Wuhan University People's Hospital (wdry2020-k064), and written informed consent was obtained from all participants before enrolment.

\section{Definitions}

Based on the Diagnosis and Treatment Guideline of 2019 New Coronavirus Pneumonia issued by the Chinese National Health Committee(Trail Version Seven), confirmed patients in our study were classified as non-severe or severe type. Patients were defined as being severe cases when they meet one of the following criteria:1)respiratory distress, respiratory rate(RR) $\geq 30$ times/min;2)oxyhemoglobin saturation $\left(\mathrm{SpO}_{2}\right)<93 \%$ at rest;3) partial pressure of oxygen/fraction of inspiration $\mathrm{O}_{2}\left(\mathrm{PaO}_{2} / \mathrm{FiO}_{2}\right) \leq 300$ $\mathrm{mmHg}$;)respiratory failure and need for mechanical assistance; shock; "extra pulmonary" organ failure, intensive care unit is needed. Otherwise, the patients were diagnosed as non-severe cases.

Based on the WHO definitions, anaemia was defined as haemoglobin level $<120 \mathrm{~g} / \mathrm{L}$ in women and $<130$ $\mathrm{g} / \mathrm{L}$ in men. Based on haemoglobin value,anaemiaseverity was categorized as mild (110-119 g/L for women and 110-129g/L for men), moderate (80-109 g/L) or severe (less than $80 \mathrm{~g} / \mathrm{L}$ ) ${ }^{[10]}$. 


\section{Data collection}

We recorded demographic information, signs and symptoms, comorbidities, routine laboratory examinations, and outcomes. All of the information was extracted from electronic medical records, or throughdirect communication with patients and healthcare providers. Two physicians independently reviewed the data, and a third researcher decided whether there was any difference in data collection between the two primary reviewers. Patients' haemoglobin levels were collected upon admission to the hospital and then patients were identified as either being anaemic or not.

\section{Laboratory measurements}

Respiratory specimens were collected from patients suspected of being infected with 2019-nCoV. Laboratory testing of the virus was performed using next-generation sequencing or real-time reverse transcription polymerase chain reaction in the clinical laboratory in Wuhan, as previously described. ${ }^{[9]}$ Only laboratory-confirmed patients were included in the study.Clinical laboratory tests were performed using conventional methods upon hospital admission, including laboratory assessments consisting of routine blood tests, coagulation profiles, inflammation profiles, cardiac function, liver function and renal function. Routine blood tests were performed within $24 \mathrm{~h}$ after admission.

\section{Statistical analysis}

Continuous variables were presented as median and interquartile range (IQR) and compared with ttest or one-way ANOVA tests if they were normally distributed; otherwise, the Mann-Whitney U test was used. Categorical variables were described as percentages and frequency rates, and compared by $\chi 2$ test or Fisher's exact test, as appropriate. Univariate logistic regression analysis was adopted to evaluate independent risk factors related to disease severity.Variables were entered into a multivariate logistic regression model by a backward elimination procedure. SPSS (version 26.0) and R(Version 3.5.3) were used for all statistical analyses. A two-sided a value of $<0.05$ was considered to indicate statistical significance. Statistical diagrams were drawn using GraphPad Prism (Version 8.3.1) and R(Version 3.5.3)

\section{Result}

\section{Demographic and clinical Characteristics of COVID-19 patients}

A total of 375 patients were admitted to hospital, and 153 cases were excluded due to having negative reverse-transcription polymerase chain reaction (RT-PCR) results $(n=144)$, age $<18(n=3)$, missing data on haemoglobin levels( $n=3$ )(Figure 1). Finally, a total of 222 cases, including 202 non-severe patients and 20 severe patients, were included in our study. Among 222 patients, 3 died. Baseline characteristics are described in Table 1. The median age of the patients was 55 years (IQR, 42-66 years); there were with $80(36.0 \%)$ male and $142(64.0 \%)$ women. Overall, $81(36.5 \%)$ patients had one or more comorbidities, of which hypertension(28.6\%)was the most common one, followed by diabetes(12.2\%), 
cardiovascular disease(CVD)(7.7\%), and chronic obstructive pulmonary disease(COPD)(3.6\%). The most common symptom at the onset of the illness was fever(59.5\%), followed by cough(54.1\%), expectoration(23.0\%), weakness(18.0\%), chest pain(15.3\%), and dysponea (13.5\%). A minority of patients initially presented with diarrhoea(9.9\%), myalgia(1.8\%), and pharyngula(1.4\%). Based on the guideline described previously, disease severity was graded as severe or non-severe, respectively. As reported by previous studies, compared with non-severe patients, severe cases were significantly older(54 years vs 65 years,$P=0.004)$ and significantly more likely to suffer from underlying disorders $(31.7 \%$ vs $85.0 \%$, $\mathrm{P}=0.000)$, such as hypertension, CVD, andCOPD.

\section{Laboratory measurement of COVID-19 patients}

Laboratory tests of COVID-19 patients were conducted at the time of admission, and the results are shown in Table2. Patients with COVID-19 presented with an inflammatory response combined with functional impairment of major organs. Differences were observed between the subgroups. Compared with non-severe patients, some indices of coagulation, cardiac, renal, and liver function, such as Ddimer,prothrombin time(PT), lactate dehydrogenase (LDH), urea nitrogen(BUN), glutamic oxiracetam transaminase(ATS), total bilirubin,were significantly elevated in severe patients(all $P<0.05)$.Moreover, inflammatory biomarkerssuch as c-reactive protein (CRP), procalcitonin(PCT), erythrocyte sedimentation rate(ESR), and neutrophil countswere higherin severe patients than in non-severe cases. Notably, $79(35.6 \%)$ patients met the diagnostic criteria foranaemia. Consistent with previous researches, in severe patients, haemoglobin levels showed a significant decline when compared to non-severe patients $(128 \mathrm{~g} / \mathrm{L}$ vs $111.5 \mathrm{~g} / \mathrm{L}, \mathrm{P}=0.002$ ). Further, significantly more patients inthe severe group met the diagnostic criteria for anaemia( $32.2 \%$ vs $70.0 \%, P=0.001)$, which is of great significance but can easily be ignored.

\section{Comparisons between patients with anaemia and without anaemia}

The diagnosis and severity of anaemia were established based on the WHO definitions ${ }^{[10]}$. Haemoglobin levels of patients with and without anaemiawere $134 \mathrm{~g} / \mathrm{L}$ and $112 \mathrm{~g} / \mathrm{L}$, respectively $(P=0.000)$ (Figure2A). In our study, the prevalence of severe illness in the anaemic group was significantly higher than that in the non-anaemicgroup ( $8.1 \%$ vs $17.7 \%, \mathrm{P}=0.001$ )(Figure2B,). Tables 3 and 4 present the differences between the subgroups. Compared with patients without anaemia, patients with anaemia were older and more likely to undergo chronic kidney disease(CKD)(0.0\% vs $3.8 \%)$, CVD (3.5\% vs $15.2 \%)$, and $\operatorname{COPD}(0.0 \%$ vs $10.1 \%)(a l l ~ P<0.05)$. Neither sex nor symptoms were significantly different between patients with anaemia and those without. In terms of laboratory testing, COVID-19 patients with anaemia were predisposed to more severe inflammatory responses, coagulation disorders, and organ injuries. More patients demonstrated elevated levels of $\operatorname{CRP}(8.5 \%$ vs $24.7 \%)$, and PCT(1.3\% vs $15.6 \%)$ in theanaemic group(all $P<0.05)$ (Figure2C,2D). Beyond that, patients with anaemia showed significantly higher levels of ESR, $D-$ dimer, myoglobin, T-pro-BNP and BUN(all $P<0.05$ ) (Figure2E).Further, most indices of blood routine including white blood cell count(WBC), lymphocyte, neutrophils, eosinophils, red blood cell count(RBC), haematocrit, and platelet count were prominently lower in theanaemicgroup compared to the non- 
anaemic group(all $\mathrm{P}<0.05$ ) (Figure 2F). Kaplan-Meier survival curve showed that patients with anaemia had lower survival rate than patients without anaemia(Log-rank test: $P=0.019)$ ( see additional file 3 ).

\section{Differences between patients with anaemia in various severity}

The severity of anaemia was established based on the WHO definitions ${ }^{[10]}$. Among the 222 patients in our study, 46 patients were classified as having mild anaemia, whereas 29 and 4 patients were classified as having moderate and severe anaemia, respectively. Haemoglobin levels of the three groups were $116 \mathrm{~g} / \mathrm{L}, 103 \mathrm{~g} / \mathrm{L}$, and $72 \mathrm{~g} / \mathrm{L}$, respectively. Compared with the mild anaemia group, patients with moderate to severe anaemiawere more likely to present with dyspnoea $(24.2 \%$ vs $6.5 \%, P=0.025)$, while no significant difference was found in the age, sex, comorbidities, proportion of severe patients, and mortality between the anaemiasubtypes (As is shown in Table3, Figure2B, additional file 1). For laboratory indices, we found that the severity of anaemia was positively associated with inflammatory responses and coagulation disorders, whereas no significant relationship with organ injuries was observed. The prevalence of CRP, PCT beyond the normal range, and elevated levels of ESR and D-dimer, were prominently higher in patients with moderate to severe anaemiacompared to patients with mild anaemia(Figure2C,2D). Moreover, the absolute values of WBC, lymphocyte count(Figure2E), eosinophils, $\mathrm{RBC}$, platelet count, haematocrit, $\mathrm{SO}_{2}$, and $\mathrm{PO}_{2}$ gradually and significantly decreased as theanaemia grade increased(all $\mathrm{P}<0.05)$.

\section{Associations between anaemia and severe illness of COVID-19}

To assess whether anaemia is a risk factors for the severe illness of COVID-19, logistic regression analysis was performed. Based on the recent studies and our statistical results, some variables among the baseline data and laboratory findings were included in the logistic regression model. As summarised in Figure3andadditional file 2, in univariate analysis, baseline data including hypertension, CVD, COPD, age $\geq 60$ years, anaemia and laboratory indices containing CRP $\geq 10 \mathrm{mg} / \mathrm{L}, \mathrm{LDH} \geq 250 \mathrm{U} / \mathrm{L}$, and D-

dimer $\geq 0.5 \mathrm{mg} / \mathrm{L}$ were significantly associated with the increased disease severity in patients with COVID19. We further screened and selected the variables to be included in the multivariable logistic regression model. The multivariable analysis indicated that anaemia remained significant as an independent risk factor for patients with severe COVID-19, even after adjusting for baseline data(OR:5.07,95\%Cl:1.82$14.18, \mathrm{P}=0.002$ ) and laboratory indexes(OR:3.47,95\% Cl:1.02-11.75, $\mathrm{P}=0.046)$. However, anaemiashowed an insignificant relationship with the overall mortality of COVID-19 patients in univariate analysis $(P=0.996)$, possibly because of the limited death toll in our cohort.

\section{Discussion}

We reported 222 patients with COVID-19 in this cohort. The clinical and laboratory features of COVID-19 patients were similar to those in other series ${ }^{[11]}$. In this retrospective cohort study, we mainly identified that COVID-19 patients with anaemia were more likely to develop severe conditions and had a higher mortality. Comorbidities were more commonly seen in patients with potential anaemia. In addition, 
anaemic patients were older and had a higher risk of severe inflammatory responses and organ injuries. Moreover, theseverity of anaemia was positively and strongly associated with more serious inflammatory responses. Our research also demonstrated that anaemia is an independent risk factor associated with severe illness of COVID-19.

Anaemiais common among patients suffering from pneumonia, with nearly 7-12\% incommunity-acquired pneumonia and $31.8 \%$ in severe influenza A. ${ }^{[6,11]}$ Zhouet al. ${ }^{[12]}$ in which 191 patients were enrolled, found that the frequency of anaemia in COVID-19 patients was $15 \%$. In a cohort of 267 patients with severe acute respiratory syndrome, $16 \%$ had anaemia at presentation, whereas the incidence increased to $53 \%$ during hospitalization. ${ }^{[13]}$ In our study, the prevalence of anaemia in hospitalisedCOVID-19 patients was up to $35.5 \%$, which is much higher than that reported by Zhou et al.Due to the limited literature on anaemiaamong COVID-19 patients, the accurate prevalence of anaemia in patients with COVID-19 remains unclear.

Anaemia commonly aggravatesthe severity of respiratory diseases, and it has been documented that respiratory diseases combined with anaemiaare associated with poor outcomes and increased mortality ${ }^{[6,7]}$. Hitherto, no research has noted the clinical characteristics of COVID-19 patients with anaemia as well as the direct correlation between anaemia and disease severity in patients with COVID19.It is worth noting the clinical characteristics in patients with and without anaemia as well as in patients with different severities of anaemia. Our study is the first investigation that exclusively and systematically focuses on anaemia in COVID-19 patients. We first described the clinical and laboratorycharacteristics of COVID-19 patients with anaemia and then further evaluated the impact of anaemia on patients with COVID-19.

The physiological mechanisms of the direct correlation observed in our cohort between anaemia and COVID-19 severity remained elusive. Previous investigations have revealed that anaemicpatientshad poorer lung function than non-anaemicpatients ${ }^{[14]}$.Additionally, it is well acknowledged that anaemia and low haemoglobincould decrease oxygen delivery. Therefore, it is plausible to speculate that COVID-19 patients with anaemia were more susceptible to severe illness due to worse pulmonary function and poor tissue oxygenation. Despite the lack of significant differences in lung function-related parameters between anaemic patients and non-anaemic patients in our study, patients with moderate to severe anaemia presented a prominently higher proportion ofdyspnea symptoms and lower levels of $\mathrm{PaO}_{2}$ and $\mathrm{SaO}_{2}$ than patients with mild anaemia. As shown in the recent autopsy reports of COVID-19 patients, macrophages, neutrophils, and lymphocytes were observed in alveolar cavities ${ }^{[15]}$.Since the increasing degree of neutrophilic infiltration was more evident in patients with anaemia, an elevated neutrophilic count might indicate serious pulmonary infiltration of inflammation, which might further degrade lung function.

In our study, myocardial injury and renal dysfunction were more remarkable in patients with anaemia. The anaemic group showed higher NT-proBNP levels and a higher proportion of elevatedcreatinine casescompared to the non-anaemic group. A possible explanation for the underlying mechanism of 
anaemia-induced organ injuries is a progressive reduction in blood oxygen content and limited tissue oxygen delivery ${ }^{[16]}$. Indeed, it has been reported that the median NT-proBNP concentration in patients with anaemia was significantly higher than in those without anaemia ${ }^{[17,18]}$. Guo et al. ${ }^{[19]}$ found that patients with underlying myocardial injury were more likely to experience cardiac dysfunction during the course of COVID-19, whereas cardiac dysfunction was significantly associated with fatal outcome of COVID-19. Additionally, Pei et al.reported that renal complications in COVID-19 were associated with poor mortality ${ }^{[20]}$. Thus, myocardial injury and renal dysfunction might potentially contribute to the greater risk of severe condition in anaemic patients with COVID-19.

Iron requirements are essential to sustain haemoglobinsynthesis, and these requirements are mostly satisfied by the iron recycling of senescent erythrocytes by macrophages ${ }^{[21]}$.ACE2, the well-established receptor of SARS-CoV-2, was confirmed to be expressed in macrophages ${ }^{[22,23]}$. SARS-CoV-2 triggers macrophages to produce IL- 6 , the essential driver of "cytokine storm syndrome" "24]. At the same time, IL- 6 increased hepcidin levels, causing iron-restricted erythropoiesis and anaemia of inflammation via the interleukin ( IL)-6/STAT3 pathway ${ }^{[25]}$.Although cytokines were not evaluated in our cohort, several studies have demonstrated that IL-6 levelswere significantly higher in severe patients than in non-severe patients, and were also strikingly associated with the severity of COVID-19 ${ }^{[26,27]}$. In our study, we observed that a significantly larger percentage of patients in anaemia group had elevated inflammation-related indicators(eg.PCT, CRP). In addition, the severeanaemia group showed a higher proportion of patients with elevated PCTand CRP levels than the mild anaemia group. Therefore, it was rational to hypothesise that more severe inflammatory responses may explain why patients with anemia were more susceptible to a severe disease course in COVID-19.

Anaemia has been an independent risk factor for adverse outcomes in various diseases, including pneumonia, stroke, and heart failure ${ }^{[28,29]}$. It has been proven thatpneumonia patients with anaemiaare at greater risk of poor outcomes and nosocomial infections in community-acquired pneumonia,and influenza $A^{[6,7,30]}$. In the study by Zhou et al, COVID-19 patients with anaemia were more susceptible to death, non-survival group showed a higher proportion of patients with anemia when compared to survival group ( $26 \%$ vs $11 \%, P=0.0094)$. In line with previous findings, anaemiawas an independent risk factor related to severe illness in COVID-19 in our cohort. It has been shown ${ }^{[31]}$ that comorbidities (eg. hypertension, CVD, COPD) and old age are strong predictors of poor outcomes in COVID-19.0ur results also showed that hypertension, CVD, COPD, and old age were associated with greater COVID-19 severity. It should be noted that, after adjustmentfor these risk factors, anaemia still had a significant adverse impact on the clinical course of COVID-19. Besides, anaemia was still identified as a risk factor even after adjustingfor laboratory findings of $\mathrm{CRP} \geq 10 \mathrm{mg} / \mathrm{L}, \mathrm{LDH} \geq 250 \mathrm{U} / \mathrm{L}$, and D-dimer $\geq 0.5 \mathrm{mg} / \mathrm{L}$ in the multivariate logistic regression model. Therefore, healthcare professionals should be more sensitive to the haemoglobin level of COVID-19 patients on admission. To avoid rapid deterioration, more intensive care should be given to patients with anaemia. 
Several limitations of this study should be acknowledged. First, only 20 patients with severe illness were included in our cohort, thus the interpretation of our findings might be limited by the relatively small sample size. Second, the diagnosis of anaemia was made based on the levels ofhaemoglobin on admission, the exact cause and duration of anaemiahowever, remained unclear. Thus, it is difficult to verify whether that SARS-CoV-2 has a direct role in anaemia. Third, we had no information on the haemoglobin levels before infection and dynamic haemoglobin levels during hospitalisation. Therefore, whether deterioration of COVID-19 occurs along with persistently declined anaemia is a question that merits further study.

\section{Conclusion}

COVID-19 patients with anaemia showed a higher rate of comorbidities, more severe inflammatory responses and organ injuries when compared with the non-anaemiccontrols. The degree of inflammatory responses in COVID-19 patients was positively associated with the severity of anaemia. Moreover, anaemia was an independent risk factor associated with severe illness in COVID-19.

\section{List Of Abbreviation}

COVID-19: corona virus disease 2019; ACE2=angiotensin-converting enzyme 2; SARS-CoV-2:severe acute respiratory syndrome coronavirus 2; SARS-CoV: severe acute respiratory syndrome coronavirus;MERS$\mathrm{CoV}$ :middle east respiratory syndrome-coronavirus; SARS:severe acute respiratory syndrome; RR:respiratory rate; $\mathrm{SpO}_{2}$ :oxyhaemoglobinSaturation; $\mathrm{PaO}_{2}$ : partial pressure of oxygen; $\mathrm{FiO}_{2}$ : fraction of inspiration $\mathrm{O}_{2}$; 2019-nCoV: 2019 novel coronavirus; WHO:world health organization; RT-PCR:reversetranscription polymerase chain reaction; CKD: chronic kidney disease; CVD: chronic cardiovascular disease; COPD: chronic obstructive pulmonary disease; $\mathrm{PaO2}$ : partial pressure of oxygen; $\mathrm{SaO2}$ : oxygen saturation; CRP: c-reactive protein: PCT:procalcitonin; ESR: erythrocyte sedimentation rate; CK-MB: creatine kinase-MB; LDH: lactate dehydrogenase; T-pro-BNP: T-pro brain natriuretic peptide; ALT: glutamicpyruvic transaminase; AST: glutamic oxiracetam transaminase; ALP: alkaline phosphatase; GGT: gamma glutamyl transpeptidase; BUN: urea nitrogen; WBC:white blood cell count; RBC:red blood cell count: IQR:inter-quartile range; OR:odd ratio; $\mathrm{Cl}$ : confidence interval.

\section{Declarations}

\section{Ethics approval and consent to participate}

The study was approved by The Ethics Commission of Wuhan University People's Hospital (wdry2020k064), and written informed consent was obtained from all participants before enrolment.

\section{Consent for publication}

Not applicable 
Availability of data and materials

The datasets used and/or analyzed during the current study are available from the corresponding author on reasonable request.

\section{Competing interests}

The authors declare that they have no competing interests.

\section{Funding}

This study was supported by National Natural Science Foundation of China (8177010121) and (8197010190) awarded to JL-L, Medical-engineering Cross Fundation of Shanghai Jiao Tong University“2019-nCoV research project”(YG2020YQ30) awarded to JL-L.

\section{Authors' contributions}

ZY-T analyzed the data and drafted the manuscript; MY-L and JY-W enrolled the patients in the project and collected the data; $\mathrm{JX}$ helped in the draft of the article; WC and ZT-Y helped enrolled the patients in the project; XM-X and LL helped collected the data; RW-C and JY-X helped in the data analysis.HM-W edited the manuscript;JL-L designed the research and revised the article. All authors read and approved the final manuscript.

\section{Acknowledgements}

We would like to thank all the patients and guardians of those patients for their participation in the study. We would also like to acknowledge the professors and colleagues from Shanghai Jiaotong University and including: XiaoLing Xi (Ruijin hospital), Bin Tang (Ruijin hospital), YaNan Sun (Ruijin hospital), Yi Cheng (Ruijin hospital), QiHan Wu (Ruijin hospital).

\section{Author details}

1 Department of Critical Care Medicine, Ruijin Hospital, Shanghai Jiao Tong University School of Medicine, Shanghai, China

2 Wuhan Ninth Hospital, Wuhan, Hubei Province, China.

3 Department of Pulmonary and Critical Care Medicine, Ruijin Hospital, Shanghai Jiaotong University School of Medicine, Shanghai, China.

4 Emergency Department, Ruijin Hospital, Shanghai Jiaotong University School of Medicine, Shanghai, China.

5 Renal Department of Wuhan Ninth Hospital, Wuhan, Hubei Province, China. 
6 Ophthalmologic Center of Renmin Hospital, Wuhan University, Wuhan, Hubei Province, China.

7 Renal Department ofRuijin Hospital, Shanghai Jiao Tong University School of Medicine, Shanghai, China

8 Renal Department of Renmin Hospital, Wuhan University, Wuhan, Hubei Province, China.

\section{Reference:}

1. Chan JF, Yuan S, Kok KH, To KK, Chu H, Yang J, Xing F, Liu J, Yip CC, Poon RW, Tsoi HW, Lo SK, Chan KH, Poon VK, Chan WM, Ip JD, Cai JP, Cheng VC, Chen H, Hui CK, Yuen KY. A familial cluster of pneumonia associated with the 2019 novel coronavirus indicating person-to-person transmission: a study of a family cluster. Lancet. 2020;395:514-23.

2. Zhu N, Zhang D, Wang W, Li X, Yang B, Song J, Zhao X, Huang B, Shi W, Lu R, Niu P, Zhan F, Ma X, Wang D, Xu W, Wu G, Gao GF, Tan W, China Novel Coronavirus I, Research T. A Novel Coronavirus from Patients with Pneumonia in China, 2019. N Engl J Med. 2020;382:727-33.

3. Coronaviridae Study Group of the International Committee on Taxonomy Of V. The species Severe acute respiratory syndrome-related coronavirus: classifying 2019-nCoV and naming it SARS-CoV-2. Nat Microbiol. 2020;5:536-44.

4. Zaki AM, Van Boheemen S, Bestebroer TM, Osterhaus AD, Fouchier RA. Isolation of a novel coronavirus from a man with pneumonia in Saudi Arabia. N Engl J Med. 2012;367:1814-20.

5. Lu R, Zhao X, Li J, Niu P, Yang B, Wu H, Wang W, Song H, Huang B, Zhu N, Bi Y, Ma X, Zhan F, Wang L, Hu T, Zhou H, Hu Z, Zhou W, Zhao L, Chen J, Meng Y, Wang J, Lin Y, Yuan J, Xie Z, Ma J, Liu WJ, Wang D, Xu W, Holmes EC, Gao GF, Wu G, Chen W, Shi W, Tan W. Genomic characterisation and epidemiology of 2019 novel coronavirus: implications for virus origins and receptor binding. Lancet. 2020;395:565-74.

6. Reade MC, Weissfeld L, Angus DC, Kellum JA, Milbrandt EB. The prevalence of anemia and its association with 90-day mortality in hospitalized community-acquired pneumonia. BMC Pulm Med. 2010;10:15.

7. Doshi SM, Rueda AM, Corrales-Medina VF, Musher DM. Anemia and community-acquired pneumococcal pneumonia. Infection. 2011;39:379-83.

8. Chen N, Zhou M, Dong X, Qu J, Gong F, Han Y, Qiu Y, Wang J, Liu Y, Wei Y, Xia J, Yu T, Zhang X, Zhang L. Epidemiological and clinical characteristics of 99 cases of 2019 novel coronavirus pneumonia in Wuhan, China: a descriptive study. Lancet. 2020;395:507-13.

9. Guan WJ, Ni ZY, Hu Y, Liang WH, Ou CQ, He JX, Liu L, Shan H, Lei CL, Hui DSC, Du B, Li LJ, Zeng G, Yuen KY, Chen RC, Tang CL, Wang T, Chen PY, Xiang J, Li SY, Wang JL, Liang ZJ, Peng YX, Wei L, Liu Y, Hu YH, Peng P, Wang JM, Liu JY, Chen Z, Li G, Zheng ZJ, Qiu SQ, Luo J, Ye CJ, Zhu SY, Zhong NS, China Medical Treatment Expert Group For C. Clinical Characteristics of Coronavirus Disease 2019 in China. N Engl J Med. 2020;382:1708-20. 
10. World Health Organization: Haemoglobin concentrations for the diagnosis of anaemia and assessment of severity. http://www.who.int/vmnis/indicators/haemoglobin_zh.pdf.

11. Zhang JJ, Dong X, Cao YY, Yuan YD, Yang YB, Yan YQ, Akdis CA, Gao YD. Clinical characteristics of 140 patients infected with SARS-CoV-2 in Wuhan, China. Allergy. 2020;

12. Zhou F, Yu T, Du RH, Fan GH, Liu Y, Liu ZB, Xiang J, Wang YM, Song B, Gu XY, Guan LL, Wei Y, Li H, Wu XD, Xu JY, Tu SJ, Zhang Y, Chen H, Cao B. Clinical course and risk factors for mortality of adult inpatients with COVID-19 in Wuhan, China: a retrospective cohort study. Lancet. 2020;395:1054-62.

13. Choi KW, Chau TN, Tsang O, Tso E, Chiu MC, Tong WL, Lee PO, Ng TK, Ng WF, Lee KC, Lam W, Yu WC, Lai JY, Lai ST, Grp PMHS. Outcomes and prognostic factors in 267 patients with severe acute respiratory syndrome in Hong Kong. Ann Intern Med. 2003;139:715-23.

14. Von Drygalski A, Biller J. Anemia in Cystic Fibrosis: Incidence, Mechanisms, and Association With Pulmonary Function and Vitamin Deficiency. Nutr Clin Pract. 2008;23:557-63.

15. Wang C, Xie J, Zhao L, Fei X, Zhang H, Tan Y, Nie X, Zhou L, Liu Z, Ren Y, Yuan L, Zhang Y, Zhang J, Liang L, Chen X, Liu X, Wang P, Han X, Weng X, Chen Y, Yu T, Zhang X, Cai J, Chen R, Shi Z, Bian X. Alveolar macrophage dysfunction and cytokine storm in the pathogenesis of two severe COVID-19 patients. EBioMedicine. 2020;57:102833.

16. Mistry N, Mazer CD, Sled JG, Lazarus AH, Cahill LS, Solish M, Zhou YQ, Romanova N, Hare AGM, Doctor A, Fisher JA, Brunt KR, Simpson JA, Hare GMT. Red blood cell antibody-induced anemia causes differential degrees of tissue hypoxia in kidney and brain. Am J Physiol-Reg I. 2018;314:R611-R22.

17. Hogenhuis J, Voors AA, Jaarsma T, Hoes AW, Hillege HL, Kragten JA, Van Veldhuisen DJ. Anaemia and renal dysfunction are independently associated with BNP and NT-proBNP levels in patients with heart failure. Eur J Heart Fail. 2007;9:787-94.

18. Willis MS, Lee ES, Grenache DG. Effect of anemia on plasma concentrations of NT-proBNP. Clin Chim Acta. 2005;358:175-81.

19. Guo T, Fan Y, Chen M, Wu X, Zhang L, He T, Wang H, Wan J, Wang X, Lu Z. Cardiovascular Implications of Fatal Outcomes of Patients With Coronavirus Disease 2019 (COVID-19). JAMA Cardiol. 2020;

20. Pei G, Zhang Z, Peng J, Liu L, Zhang C, Yu C, Ma Z, Huang Y, Liu W, Yao Y, Zeng R, Xu G. Renal Involvement and Early Prognosis in Patients with COVID-19 Pneumonia. J Am Soc Nephrol. 2020;31:1157-65.

21. Muckenthaler MU, Rivella S, Hentze MW, Galy B. A Red Carpet for Iron Metabolism. Cell. 2017;168:344-61.

22. Abassi Z, Knaney Y, Karram T, Heyman SN. The Lung Macrophage in SARS-CoV-2 Infection: A Friend or a Foe? Front Immunol. 2020;11:1312.

23. Hoffmann M, Kleine-Weber H, Schroeder S, Kruger N, Herrler T, Erichsen S, Schiergens TS, Herrler G, Wu NH, Nitsche A, Muller MA, Drosten C, Pohlmann S. SARS-CoV-2 Cell Entry Depends on ACE2 and TMPRSS2 and Is Blocked by a Clinically Proven Protease Inhibitor. Cell. 2020;181:271-+. 
24. Zhang C, Wu Z, Li JW, Zhao H, Wang GQ. Cytokine release syndrome in severe COVID-19: interleukin6 receptor antagonist tocilizumab may be the key to reduce mortality. Int J Antimicrob Agents. 2020;55:105954.

25. Camaschella C, Nai A, Silvestri L. Iron metabolism and iron disorders revisited in the hepcidin era. Haematologica. 2020;105:260-72.

26. Mcelvaney OJ, Mcevoy N, Mcelvaney OF, Carroll TP, Murphy MP, Dunlea DM, Ni Choileain O, Clarke J, O'connor E, Hogan G, Ryan D, Sulaiman I, Gunaratnam C, Branagan P, O'brien ME, Morgan RK, Costello RW, Hurley K, Walsh S, De Barra E, Mcnally C, Mcconkey S, Boland F, Galvin S, Kiernan F, O'rourke J, Dwyer R, Power M, Geoghegan P, Larkin C, O'leary RA, Freeman J, Gaffney A, Marsh B, Curley GF, Mcelvaney NG. Characterization of the Inflammatory Response to Severe COVID-19 IIIness. Am J Respir Crit Care Med. 2020;

27. Li X, Xu S, Yu M, Wang K, Tao Y, Zhou Y, Shi J, Zhou M, Wu B, Yang Z, Zhang C, Yue J, Zhang Z, Renz $\mathrm{H}$, Liu X, Xie J, Xie M, Zhao J. Risk factors for severity and mortality in adult COVID-19 inpatients in Wuhan. J Allergy Clin Immunol. 2020;

28. Wei CC, Zhang ST, Tan G, Zhang SH, Liu M. Impact of anemia on in-hospital complications after ischemic stroke. Eur J Neurol. 2018;25:768-74.

29. Tim Goodnough L, Comin-Colet J, Leal-Noval S, Ozawa S, Takere J, Henry D, Javidroozi M, Hohmuth B, Bisbe E, Gross I, Shander A. Management of anemia in patients with congestive heart failure. Am J Hematol. 2017;92:88-93.

30. Moschovis PP, Banajeh S, Macleod WB, Saha S, Hayden D, Christiani DC, Mino G, Santosham M, Thea DM, Qazi S, Hibberd PL. Childhood Anemia at High Altitude: Risk Factors for Poor Outcomes in Severe Pneumonia. Pediatrics. 2013;132:E1156-E62.

31. Du RH, Liang LR, Yang CQ, Wang W, Cao TZ, Li M, Guo GY, Du J, Zheng CL, Zhu Q, Hu M, Li XY, Peng P, Shi HZ. Predictors of mortality for patients with COVID-19 pneumonia caused by SARS-CoV-2: a prospective cohort study. Eur Respir J. 2020;55:

\section{Tables}


Table 1 The baseline characteristics of COVID-19 patients between severe group and non-severe group

No./total no.(\%)

All patients Disease severity

$(n=222)$

Non-severe

Severe

$P$ value $(n=202) \quad(n=20)$

Age, median(IQR),y

$55(42-66)$

54(41-66)

65(57-81)

0.004

Sex-No,\%

0.699

Male

80(36.0)

72(35.6)

8(40.0)

Female

142(64.0)

130(64.4)

12(60.0)

Signs and symptoms-No, \%

\begin{tabular}{lllll} 
Fever & $132(59.5)$ & $117(57.9)$ & $15(75.0)$ & 0.138 \\
\hline Cough & $120(54.1)$ & $108(53.5)$ & $12(60.0)$ & 0.576 \\
\hline Expectoration & $51(23.0)$ & $45(22.3)$ & $6(30.0)$ & 0.434 \\
\hline Pharyngula & $3(1.4)$ & $3(1.5)$ & $0(0.0)$ & 1.000 \\
\hline Dyspnoea & $30(13.5)$ & $24(11.9)$ & $6(30.0)$ & 0.024 \\
\hline Chest pain & $34(15.3)$ & $30(14.9)$ & $4(20.0)$ & 0.542 \\
\hline Myalgia & $4(1.8)$ & $4(2.0)$ & $0(0.0)$ & 1.000 \\
\hline Diarrhoea & $22(9.9)$ & $21(10.4)$ & $1(5.0)$ & 0.441 \\
\hline Weakness & $40(18.0)$ & $37(18.3)$ & $3(15.0)$ & 0.713
\end{tabular}

\section{Comorbidities-No, \%}

\begin{tabular}{|c|c|c|c|c|}
\hline Hypertension & $63(28.4)$ & $51(25.2)$ & $12(60.0)$ & 0.001 \\
\hline Diabetes & $27(12.2)$ & $25(12.4)$ & $2(10.0)$ & 0.756 \\
\hline CKD & $3(1.4)$ & $2(1.0)$ & $1(5.0)$ & 0.248 \\
\hline CVD & $17(7.7)$ & $11(5.4)$ & $6(30.0)$ & 0.000 \\
\hline COPD & $8(3.6)$ & $5(2.5)$ & $3(15.0)$ & 0.004 \\
\hline Death & $3(1.4)$ & $0(0.0)$ & $3(15.0)$ & 0.001 \\
\hline Mechanical ventilation & $2(0.9)$ & $0(0.0)$ & $2(10.0)$ & 0.008 \\
\hline
\end{tabular}


Page 16/25 
Table 2

Laboratory findings of COVID-19 patients on admission between severe group and non-severe group

Median (IQR)

Disease severity

$\begin{array}{llll}\text { All patients } & \text { Non-severe } & \text { Severe } & P \\ (n=222) & (n=202) & (n=20) & \text { value }\end{array}$

\section{Blood routine}

White blood cell count, $\times 10^{9} / \mathrm{L}$

$6.2(5.2-7.5)$

$6.2(5.2-7.5)$

$6.4(5.7-8.4)$

0.346

Lymphocyte count, $\times 10^{9} / \mathrm{L}$

1.7(1.3-2.2)

1.8(1.4-2.2)

$0.87(0.71-1.5)$

0.000

Neutrophil count, $\times 10^{9} / \mathrm{L}$

3.7(3-5)

3.6(3-4.8)

$5.2(3.5-7.1)$

0.014

Monocyte count, $\times 10^{9} / \mathrm{L}$

0.47(0.37-0.57)

$0.47(0.37-0.56)$

$0.48(0.36-0.61)$

0.884

Eosinophil count, $\times 10^{9} / \mathrm{L}$

0.08(0.05-0.16)

0.09(0.06-0.16)

$0.03(0.01-0.08)$

0.000

Basophils count, $\times 10^{9} / \mathrm{L}$

$0.01(0.01-0.02)$

$0.01(0.01-0.02)$

$0.01(0-0.02)$

0.050

Red blood cell count, $\times 10^{9} / \mathrm{L}$

4.3(3.9-4.6)

4.3(3.9-4.6)

3.8(3.6-4.2)

0.002

Haemoglobin, g/L

$127.0(116.0-$

137.0)

128(118-137)

111.5(104-128.3)

0.002

Hematocrit

39.0(35.7-41.6)

39.1(36.3-41.7)

34.1(31.9-39.7)

0.003

Platelet count, $\times 109 / \mathrm{L}$

228.0(183.0-

279.8)

229.5(188-

280.8)

193.0(169.5-

267.3)

$\mathrm{PaO}_{2}, \mathrm{mmHg}$

92.5(77.5-138.8)

89.0(76.0-

131.0)

95.0(86.5-186.5) $\quad 0.292$

98.0(97.0-98.3)

98.0(97.0-100.0)

0.291

$\mathrm{SaO}_{2}, \%$

98.0(97.0-99.0)

(98.0(97.0-98.3)

\section{Coagulation function}

Prothrombin time,s

11(10.7-11.6)

11(10.6-11.5)

11.4(11.1-12.2)

0.013

Activated partial thrombin

27.4(25.3-30.2)

27.4(25.3-30.1)

28(25.3-33.4)

0.510 time,s

D-dimer, $\mu \mathrm{g} / \mathrm{mL}$

$0.5(0.3-0.63)$

0.5(0.3-0.6)

$0.9(0.5-1.4)$

0.000

\section{Inflammation profile}

\begin{tabular}{lllll} 
C-reactive protein mg/L & $1.9(1.5-3.9)$ & $1.8(1.5-3)$ & $46.8(2.8-76)$ & 0.000 \\
\hline Procalcitonin , ng/mL & $0.02(0.01-0.07)$ & $0.02(0.01-0.06)$ & $0.06(0.02-0.46)$ & 0.005 \\
\hline Blood lactic acid, mmol/L & $1.4(1-1.9)$ & $1.3(1-1.9)$ & $1.6(1-2)$ & 0.769
\end{tabular}




\begin{tabular}{|c|c|c|c|c|}
\hline $\mathrm{ESR}, \mathrm{mmol} / \mathrm{L}$ & $11(6.5-23.5)$ & $10(6-21)$ & $42(22.3-73)$ & 0.005 \\
\hline \multicolumn{5}{|l|}{ Cardiac function } \\
\hline Myoglobin, ng/ml & 18(11.2-35.4) & 18(11.2-34.1) & $21.5(10-42.4)$ & 0.719 \\
\hline CK-MB, $\mu \mathrm{g} / \mathrm{mL}$ & $2.6(1-7.5)$ & $2.6(1.1-8.5)$ & $2.5(1-4)$ & 0.476 \\
\hline $\mathrm{LDH}, \mathrm{U} / \mathrm{L}$ & 178(145.3-211.8) & $\begin{array}{l}173(144.5- \\
203.5)\end{array}$ & 261(204-395.5) & 0.000 \\
\hline T-pro-BNP, pg/mL & $120(16-1422)$ & $88(15-489.8)$ & 524(31.3-1876.5) & 0.242 \\
\hline \multicolumn{5}{|l|}{ Liver function } \\
\hline$A L T, U / L$ & 18(13-30.8) & 18(13-30) & $27(11.8-32.5)$ & 0.465 \\
\hline AST ,U/L & $22.5(18-28)$ & $22(18-28)$ & $31.5(17.8-48.3)$ & 0.027 \\
\hline Total bilirubin, $\mu \mathrm{mol} / \mathrm{L}$ & 10.1(8.3-13.3) & $9.8(8.2-13.1)$ & 14.5(10.4-18.5) & 0.001 \\
\hline ALP,U/L & $83(70-102)$ & $83(70-101)$ & 79(69.5-103.3) & 0.704 \\
\hline GGT,U/L & $20(12.3-30.8)$ & $18.5(12-28)$ & 27.5(18.8-40.3) & 0.064 \\
\hline \multicolumn{5}{|l|}{ Renal function } \\
\hline $\mathrm{BUN}, \mathrm{mmol} / \mathrm{L}$ & $4.4(3.7-5.8)$ & $4.3(3.7-5.6)$ & $5.9(3.6-7.5)$ & 0.044 \\
\hline $\begin{array}{l}\text { Creatinine } \geq 133 \mu \mathrm{mol} / \mathrm{L}-\mathrm{No} \text {, } \\
\%\end{array}$ & $6(2.7)$ & $3(1.5)$ & $3(15.0)$ & 0.000 \\
\hline Uric Acid, $\mu \mathrm{mol} / \mathrm{L}$ & $289(240-353)$ & $289(236-349)$ & $296(259.5-400.5)$ & 0.351 \\
\hline \multicolumn{5}{|c|}{$\begin{array}{l}\text { Data are presented as No./total No.(\%) and median (IQR), P values were calculated by Mann-Whitney } \\
\text { U test, } t \text { test, } x 2 \text { test, or Fisher's exact test, as appropriate. P values denoted the comparison between } \\
\text { severe group and non-severe group. COVID-19: coronavirus disease 2019; PaO2: partial pressure of } \\
\text { oxygen; SaO2: oxygen saturation; ESR:erythrocyte sedimentation rate; CK-MB: creatine kinase-MB; } \\
\text { LDH: lactate dehydrogenase; T-pro-BNP:T-pro brain natriuretic peptide; ALT: glutamic-pyruvic } \\
\text { transaminase;AST: glutamic oxiracetamtransaminase; ALP: alkaline phosphatase; GGT: gamma- } \\
\text { glutamyl transpeptidase; BUN: urea nitrogen }\end{array}$} \\
\hline
\end{tabular}


Table 3 The baseline characteristics of COVID-19 patients with or without anaemia on admission

No./total No.(\%)

Anaemia

Severityof Anaemia

$\begin{array}{llllll}\text { No } & \text { YES } & P & \text { Mild } & \begin{array}{l}\text { Moderate to } \\ \text { severe } \\ (n=143)\end{array} & \begin{array}{l}\text { value } \\ (n=79)\end{array}\end{array}$

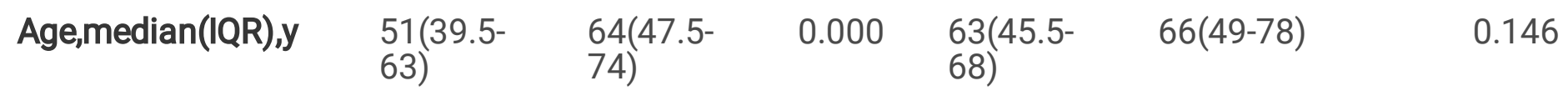

Sex-No,\%

0.471

0.946

Male

54(37.8) 26(32.9)

15(32.6) 11(33.3)

Female

$89(62.2) \quad 53(67.1)$

31(67.4) 22(66.7)

\section{Signs and \\ symptoms}

- No, \%

\begin{tabular}{lllllll} 
Fever & $86(60.1)$ & $46(58.2)$ & 0.781 & $26(56.5)$ & $20(60.6)$ & 0.717 \\
\hline Cough & $79(55.2)$ & $41(51.9)$ & 0.632 & $23(50.0)$ & $18(54.4)$ & 0.690 \\
\hline Expectoration & $37(25.9)$ & $14(17.7)$ & 0.167 & $8(17.4)$ & $6(18.2)$ & 0.928 \\
\hline Pharyngula & $2(1.4)$ & $1(1.3)$ & 1.000 & $1(2.2)$ & $0(0.0)$ & 1.000 \\
\hline Dyspnoea & $19(13.3)$ & $11(13.9)$ & 0.894 & $3(6.5)$ & $8(24.2)$ & 0.025 \\
\hline Chest pain & $22(15.4)$ & $12(15.2)$ & 0.969 & $7(15.2)$ & $5(15.2)$ & 0.994 \\
\hline Myalgia & $3(2.1)$ & $1(1.3)$ & 1.000 & $1(2.2)$ & $0(0.0)$ & 1.000 \\
\hline Diarrhoea & $12(8.4)$ & $10(12.7)$ & 0.308 & $8(17.4)$ & $2(6.1)$ & 0.135 \\
\hline Weakness & $25(17.5)$ & $15(19.0)$ & 0.780 & $8(17.4)$ & $7(21.2)$ & 0.669 \\
\hline Comorbidities-No, \% & & & & & & 0.629 \\
\hline Hypertension & $39(27.3)$ & $24(30.4)$ & 0.623 & $13(28.3)$ & $11(33.3)$ & 0.207 \\
\hline Diabetes & $15(10.5)$ & $12(15.2)$ & 0.305 & $5(10.9)$ & $7(21.2)$ & 0.568 \\
\hline CKD & $0(0.0)$ & $3(3.8)$ & 0.044 & $1(2.2)$ & $2(6.1)$ & 0.207 \\
\hline CVD & $5(3.5)$ & $12(15.2)$ & 0.002 & $5(10.9)$ & $7(21.2)$ & 1.000 \\
\hline COPD & $0(0.0)$ & $8(10.1)$ & 0.000 & $5(10.9)$ & $3(9.1)$ & 0.568 \\
\hline Death & $0(0.0)$ & $3(3.8)$ & 0.044 & $1(2.2)$ & $2(6.1)$ & $1(3.0)$ \\
\hline Mechanical & $0(0.0)$ & $2(2.5)$ & 0.126 & $1(2.2)$ & & \\
\hline & & & $19 / 25$ & & & \\
\hline
\end{tabular}


Data are presented as No./total No.(\%) and median (IQR), P values were calculated by Mann-Whitney $\mathrm{U}$ test, $\mathrm{t}$ test, $\mathrm{\chi} 2$ test, or Fisher's exact test, asappropriate. $\mathrm{P}$ valuesdenoted the comparison between anaemicgroup and non-anaemicgroup, the comparison between patients with mild anaemia and patients with moderate to severe anaemia, respectively. COVID-19: coronavirus disease 2019; CKD:chronic kidney disease;CVD: chronic cardiovascular disease; COPD: chronic obstructive pulmonary disease 
Table 4 The laboratory findings of COVID-19 patients with or without anaemia on admission

\section{Anaemia}

Median (IQR)
Severityof Anaemia

$\begin{array}{llll}\text { No } & \text { YES } & \text { P } & \text { Mild } \\ (n=143) & (n=79) & \text { value } & (n=46)\end{array}$

Moderate to severe

$(n=33)$

\section{Blood routine}

White blood cell

$6.6(5.5-7.7)$

$5.8(4.7-6.8)$

$0.001 \quad 5.9(5.2-6.8)$

$5.1(3.6-6.8)$

0.078

count, $\times 10^{9} / \mathrm{L}$

Lymphocytecount, $\times 10^{9} / \mathrm{L}$

Neutrophil

count, $\times 10^{9} / \mathrm{L}$

Monocyte

count, $\times 10^{9} / \mathrm{L}$

$0.48(0.38-$

0.58 )

4.1(3.2-5.2)

3.4(2.6-4.3)

$0.000 \quad 1.6(1.4-2)$

$1(0.8-1.5)$

0.000

Eosinophil

count, $\times 10^{9} / \mathrm{L}$

$0.1(0.06-$

0.16 )

$0.45(0.34-$

0.56 )

$0.007 \quad 3.5(3-4.1)$

$3.4(2.3-5.2)$

0.496

Basophils

count, $\times 10^{9} / \mathrm{L}$

$0.01(0.01-$

0.02 )

$0.07(0.04-$

0.14 )

$0.125 \quad 0.46(0.36-$

0.56 )

$0.44(0.31-$

0.315

Red blood cell

count, $\times 10^{9} / \mathrm{L}$

Haemoglobin, g/L

4.4(4.2-4.7)

$0.01(0.01-$

0.02 )

0.039

0.08(0.06-

$0.16)$

$0.55)$

P value

140)

112(104-

117)

$0.926 \quad 0.01(0.01-$

0.02 )

$0.04(0.02-$
$0.08)$

0.012

Hematocrit

40.9(39-

42.4)

34.4(32.4-

36.4)

Platelet

count, $\times 109 / L$

233(198.5-

283.5)

210(169-

260.5)

$0.000 \quad 3.9(3.7-4.1)$

3.6(3.2-3.8)

0.000

$\mathrm{PaO}_{2}, \mathrm{mmHg}$

87.5(77.5-

103.5)

95(83-

163.8)

0.000 116(113-

118)

$101(86-106) \quad 0.000$

$\mathrm{SaO}_{2}, \%$

98(96-98)

98(97-99)

0.138

36(34.6-

37.1)

32.2(28.5-

32.6)

$0.01(0.01-$

0.051

$0.02)$

230(181.5-

269)

197(151-

240)

155.5(93.5-

238.5)

80(65.8-

103.3)

98.5(97-

100)

97.5(95-98)

0.014

\section{Coagulation}

function

$\begin{array}{cllllll}\text { Prothrombin time,s } & \begin{array}{l}10.9(10.6- \\ 11.4)\end{array} & \begin{array}{l}11.3(10.8- \\ 11.9)\end{array} & 0.002 & \begin{array}{l}11(10.7- \\ 11.6)\end{array} & \begin{array}{l}11.6(11.3- \\ 12.3)\end{array} & 0.003 \\ & & & & \\ \text { Activated partial } & 27.4(25.4- & 27.6(25.1- & 0.726 & 27.9(25.6- & 27.2(24.8- & 0.830 \\ \text { thrombin time,s } & 29.9) & 31.8) & & 30.2) & 32.1) & \end{array}$


D-dimer,jgg/mL

0.4(0.3-0.5) $\quad 0.5(0.4-$

$0.003 \quad 0.5(0.4-0.6)$

$0.8(0.45-$

0.011

$0.93)$

2.3)

\section{Inflammation} profile

C-reactive

protein.mg/L

$\geq 10 \mathrm{mg} / \mathrm{L}-\mathrm{No}, \% \quad$ 12(8.5)

Procalcitonin

, $\mathrm{ng} / \mathrm{mL}$

$\geq 0.5 \mathrm{ng} / \mathrm{mL}-\mathrm{No}, \% \quad 1(1.3)$

Blood lactic acid,

$\mathrm{mmol} / \mathrm{L}$

$\mathrm{ESR}, \mathrm{mmol} / \mathrm{L}$

Cardiac function

Myoglobin, ng/ml

12.2(8.9-

20.2)

$1.4(1.2-2)$

10(5-15)

2(1-9)

178.5(147.3-

206.3)

T-pro-BNP, pg/mL $\quad$ 16(15-85)
28.5(15.3- $\quad 0.028 \quad 23.1(15.4-$

38.6)

$3.1(2-5.2)$

$177.5(143.8$

212)

513(81.5-

2894)
40.2)

$0.565 \quad 3.4(2.1-7)$

$0.788 \quad 177(144.5-$

206.5)

$0.000309(112.8-$

900)
$30.5(17.3-$

38)

$0.04(0.01-$

$0.15)$

14/32(43.8) $\quad 0.001$

6/21(28.6) $\quad 0.024$

1.1(0.9-1.8) 0.295

$35(9.5-73)$

0.040

\section{Liver function}

\begin{tabular}{|c|c|c|c|c|c|c|}
\hline$A L T, U / L$ & $\begin{array}{l}19(14.5- \\
33.5)\end{array}$ & $17(11-26.5)$ & 0.002 & $\begin{array}{l}17.5(11.3- \\
28.8)\end{array}$ & $14(10-22)$ & 0.230 \\
\hline$A S T, U / L$ & $23(19-28.5)$ & $21(18-28)$ & 0.255 & $21(18-28)$ & $20(17-28)$ & 0.992 \\
\hline $\begin{array}{l}\text { Total bilirubin, } \\
\mu \mathrm{mol} / \mathrm{L}\end{array}$ & $\begin{array}{l}10.2(8.5- \\
13.5)\end{array}$ & $\begin{array}{l}9.5(8.2- \\
13.2)\end{array}$ & 0.408 & $\begin{array}{l}9.1(7.7- \\
12.1)\end{array}$ & $\begin{array}{l}10.6(8.5- \\
14.7)\end{array}$ & 0.116 \\
\hline ALP,U/L & $\begin{array}{l}87(72- \\
102.8)\end{array}$ & $\begin{array}{l}79(67.5- \\
100)\end{array}$ & 0.070 & $\begin{array}{l}80(70.5- \\
98.8)\end{array}$ & $73(64-102)$ & 0.426 \\
\hline GGT,U/L & $21(14-31.5)$ & $16(11.5-27)$ & 0.025 & $17.5(12-24)$ & 15(11-33) & 0.877 \\
\hline \multicolumn{7}{|l|}{ Renal function } \\
\hline $\mathrm{BUN}, \mathrm{mmol} / \mathrm{L}$ & $4.3(3.7-5.1)$ & $5.1(3.8-7.2)$ & 0.011 & $4.2(3.7-6.2)$ & $5.9(3.8-8.3)$ & 0.096 \\
\hline $\begin{array}{l}\text { Creatinine } \geq 133 \\
\mu \mathrm{mol} / \mathrm{L}-\mathrm{No}, \%\end{array}$ & $1(0.7)$ & $5(6.3)$ & 0.023 & $1(2.2)$ & $4(12.1)$ & 0.155 \\
\hline Uric Acid, $\mu \mathrm{mol} / \mathrm{L}$ & $\begin{array}{l}292(250.8- \\
359)\end{array}$ & $\begin{array}{l}276(230.5- \\
336.5)\end{array}$ & 0.257 & $\begin{array}{l}293.5(236.5- \\
342.8)\end{array}$ & $\begin{array}{l}261(216- \\
320)\end{array}$ & 0.167 \\
\hline
\end{tabular}


Data are presented as No./total No.(\%) and median (IQR), P values were calculated by Mann-Whitney $U$ test, $t$ test, $\chi 2$ test, or Fisher's exact test, as appropriate. $P$ values denoted the comparison between anaemicgroup and non-anaemic group, the comparison between patients with mild anaemia and patients with moderate to severe anaemia, respectively; COVID-19: coronavirus disease 2019; PaO2: partial pressure of oxygen; SaO2: oxygen saturation; ESR:erythrocyte sedimentation rate; CK-MB: creatine kinase-MB; LDH: lactate dehydrogenase; T-pro-BNP:T-pro brain natriuretic peptide; ALT: glutamic-pyruvic transaminase;AST: glutamic oxiracetam transaminase; ALP: alkaline phosphatase; GGT: gamma-glutamyl transpeptidase; BUN: urea nitrogen

\section{Figures}

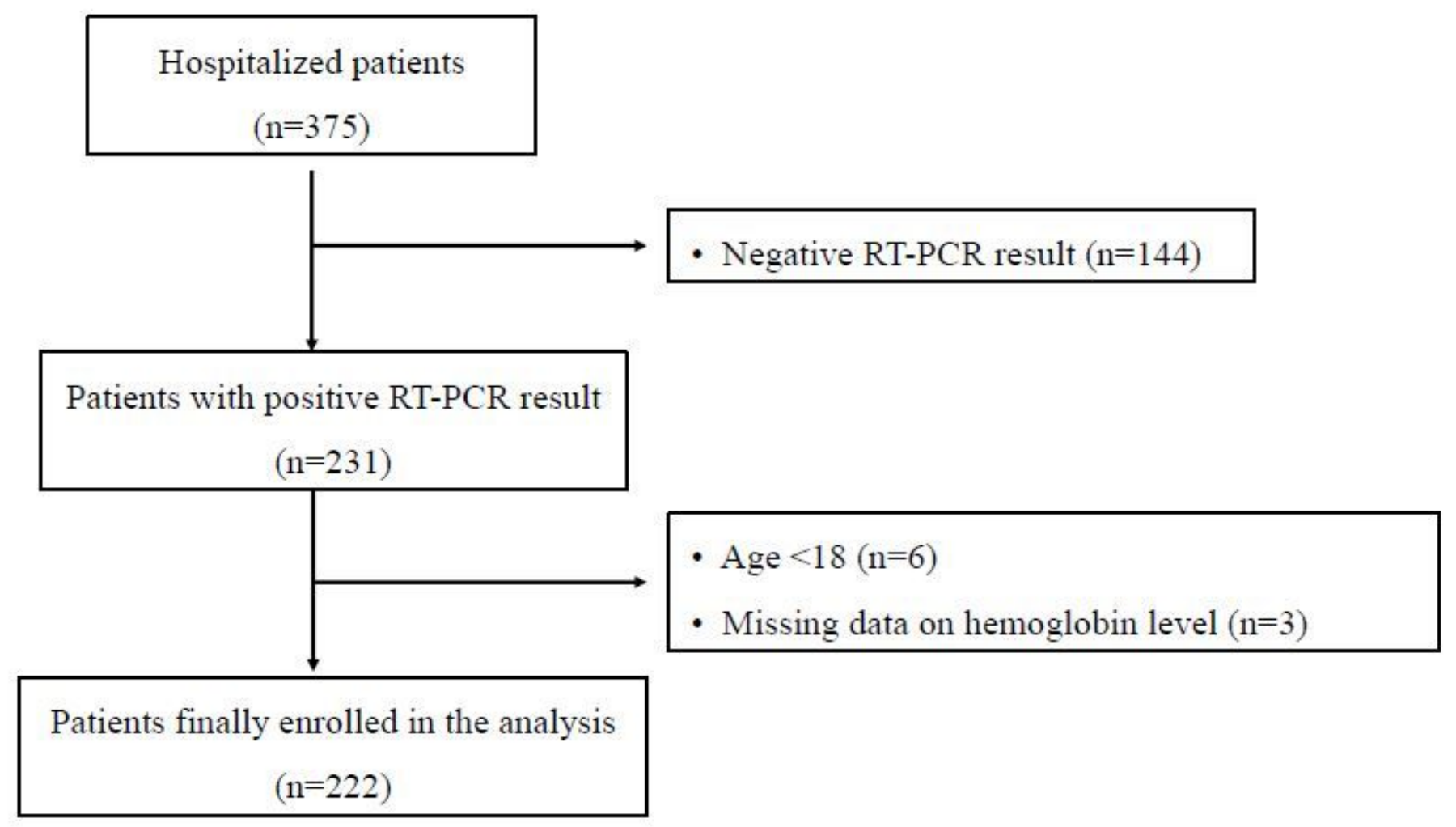

\section{Figure 1}

flow diagram for the study. RT-PCR: reverse-transcription polymerase chain reaction. 


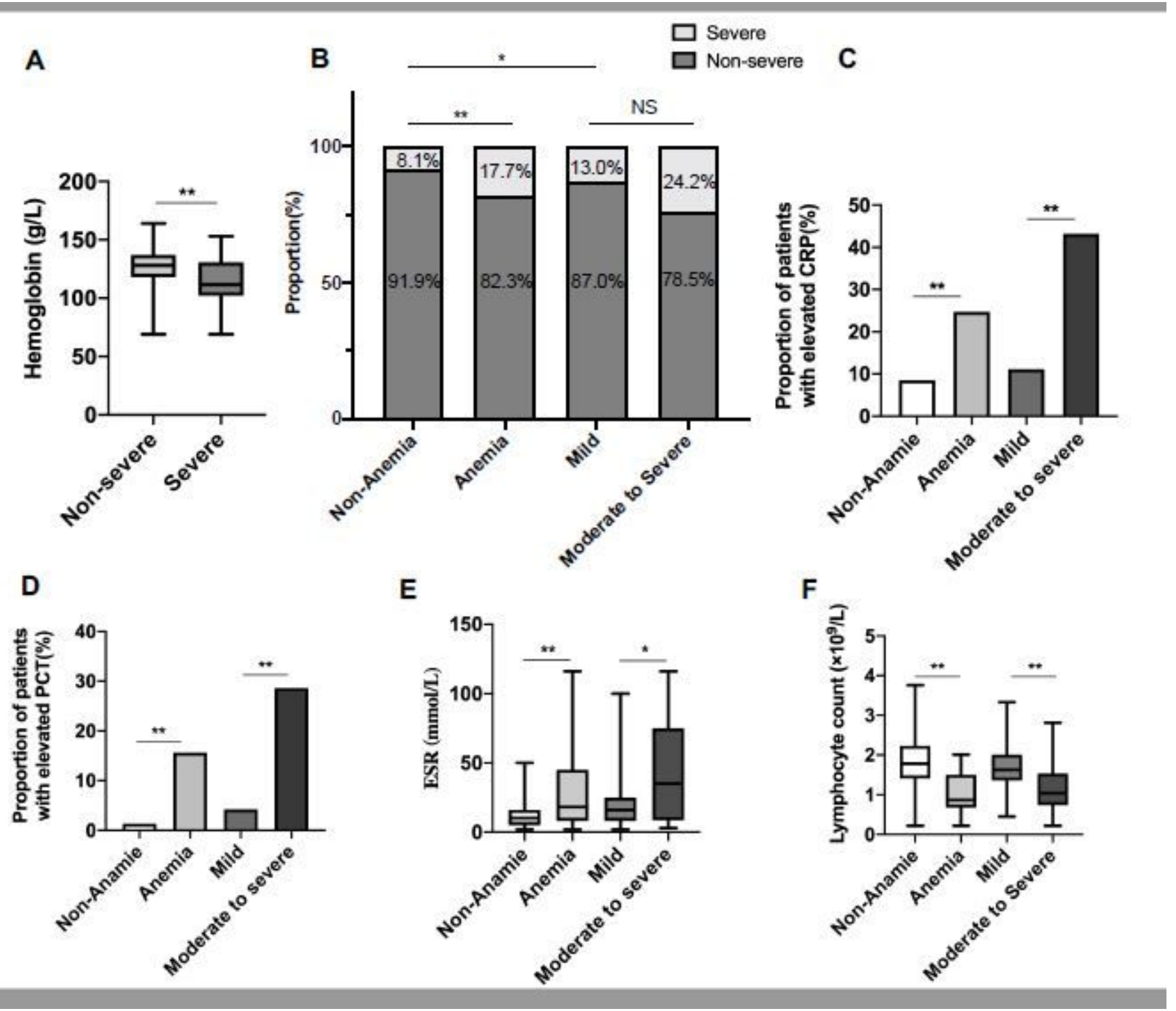

Figure 2

A: Haemoglobinlevels between severe and non-severe group. B: Prevalence of clinical subtypes of COVID19 severity among patients with and without anaemia as well as patients with different severity of anaemia. C,D,E, F: Significant laboratorial findings including c-reactive protein, erythrocyte sedimentation rate and lymphocyte count among patients with and without anaemia as well as patients with different severity of anaemia. ${ }^{*} p<0.05 ; * *: p<0.01 ; * \star * p<0.001$ 


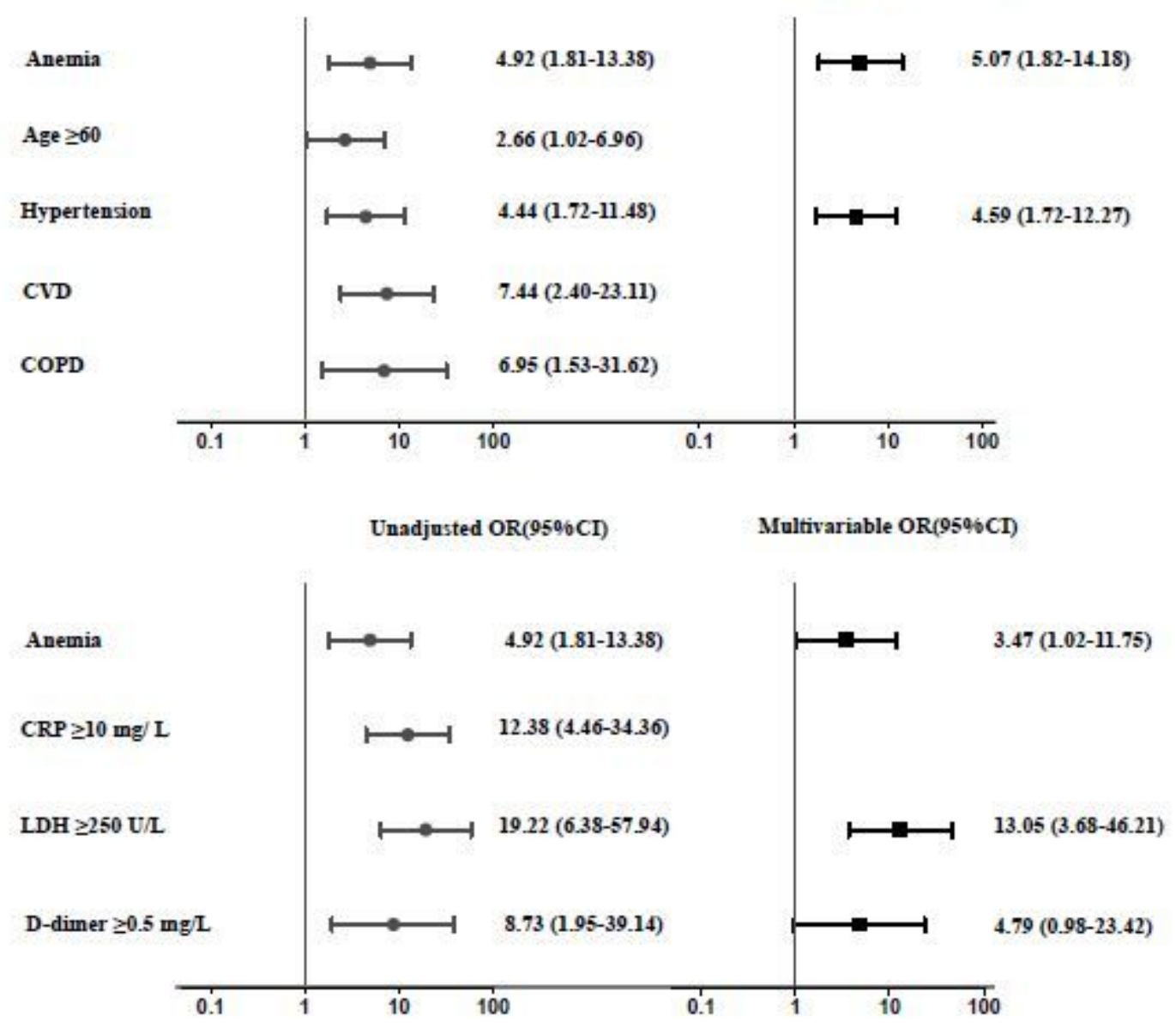

\section{Figure 3}

Univariate and multivariatelogistic analysis associated with severe illness in COVID-19. Odds ratios were calculated by univariate and multivariate logistic regression. The x-axis is on a log scale. Variables with $\mathrm{P}<0.05$ were defined as potential risk factors and included in multivariate regression analysis by a backward elimination procedure. CVD: Chronic Cardiovascular Disease; COPD: Chronic Obstructive Pulmonary Disease; CRP:C-reactive protein; LDH: Lactate Dehydrogenase

\section{Supplementary Files}

This is a list of supplementary files associated with this preprint. Click to download.

- Additionalfile3.docx

- Additionalfile2.docx

- Additionalfile1.docx 